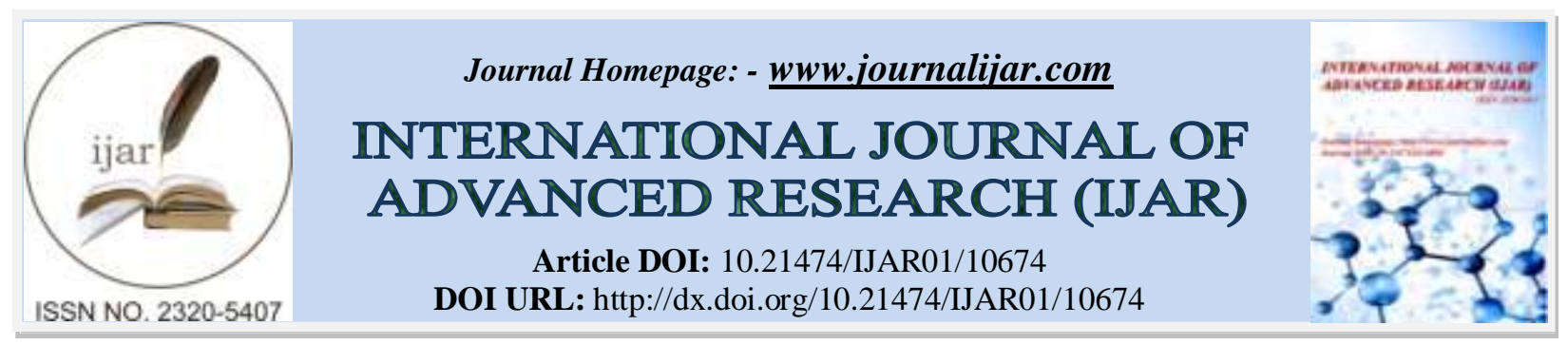

RESEARCH ARTICLE

\title{
FFA CHANGES IN CENTRAL SEROUS CHORIO RETINOPATHY
}

\author{
Dr. Rajeevan P. ${ }^{1}$ and Riswan Rasheed ${ }^{2}$ \\ 1. Additional Professor, Regional Institute of Ophthalmology, Govt: Medical College Trivandrum. \\ 2. Optometry Intern. Rio Trivandrum.
}

\section{Manuscript Info \\ Manuscript History \\ Received: 15 January 2020 \\ Final Accepted: 17 February 2020 \\ Published: March 2020}

\section{Abstract}

Copy Right, IJAR, 2020,. All rights reserved.

\section{Introduction:-}

Central serous retinopathy or central serous chorio- retinopathy (CSR/CSCR) is a condition of unknown origin characterized by serous detachment of macula with or without retinal pigment epithelium (RPE) detachment. It affects young healthy adults, mostly men between the ages of 20 and 50 years. It is usually unilateral and patient present with the complaints of blurring of vision, metamorphopsia and relative scotoma. CSR has also documented to be associated with type A personalities, cortico-steroid use and hypertension among other systemic conditions.

The cause of this disease with its marked subjective symptoms occurring in apparently healthy individuals has aroused much speculation. But the etiology of the entity is not generally agreed upon even now. A recent study of choroidal perfusion suggests that choroidal ischemia might play a role in its pathogenesis. One of the major obstacles to the elucidation of the pathogenesis is paucity of pathologic material.

Many investigators felt that treatment is never indicated since most remit spontaneously. On the other hand, prolonged periods of macular detachment may lead secondary cystic and degenerative changes with permanent visual impairment. At this time laser photocoagulation and photodynamic therapy (PDT) are the most effective treatment option.

Fundus fluorescein angiography (FFA) findings are very important in the diagnosis of CSCR. In CSCR, there is a breakdown of the outer blood retinal barrier which allows the passage of free fluorescein molecules into the subretinal space. Various patterns of dye leakage are seen. The most common are smoke-stack and ink blot. The unusual forms are inverse smoke stack, diffuse RPE leakage (ooze) and RPE atrophic tracts.

Much remains to be learned about the essential etiology and precise pathogenesis of this condition. The objective of this study is to determine the angiographic changes of CSCR. An honest effort is made in this study to determine the FFA changes of CSCR in Regional Institute of Ophthalmology, Govt. Medical College, Thiruvananthapuram.

Corresponding Author:- Dr. Rajeevan P.

Address:- Additional Professor, Regional Institute of Ophthalmology, Govt: Medical College Trivandrum. 


\begin{abstract}
Aim of Study:
To study the pattern of Central Serous Chorio Retinopathy (CSCR) on fundus fluorescence angiography (FFA).
\end{abstract}

Several cases of CSCR are being treated in Regional Institute of Ophthalmology (RIO), Thiruvananthapuram every year. These cases are being investigated thoroughly and are being treated as outpatients. The indicated cases of CSCR are subjected to fundus fluorescein angiography and in cases where leakage is detected away from the foveal avascular zone, laser photocoagulation is done in the next sitting.

\title{
Materials and Methods:-
}

\section{Criteria of Selection of Cases:}

The hospital based descriptive study of 30 patients was conducted at Regional Institute of Ophthalmology (RIO), Govt: Medical college, Thiruvananthapuram from ...1-1-2017 to 31-12-2019. in patients attending the outpatient department of RIO complaining of sudden dimness of vision, positive scotoma in the field of vision and distortion of vision, fundus examination was done thoroughly, cases selected as CSCR were those in which there is no other macular pathology except for the macular oedema. In each case, an attempt was made to find out all the salient points regarding the mode of onset of the disease, past illness if any, occupation and habits of the patient. Visual acuity in both eyes were recorded and any improvement with a week convex spherical lens is looked for. Detailed examination of fundus is done after dilating the pupils with Tropicamide. External examination of the eyes was done and slit lamp examinations were also carried out to rule out other ocular pathologies. Central field was charted and Amsler charts are given and any distortion is noted. Photo stress test and colour vision is determined. General examination was done to rule out systemic diseases. Ten the following investigations are done.

1. Blood - Hb-WBC-Total Count-Differential count \& Platelet count.

2. ESR

3. VDRL

4. Random Blood Sugar

5. Serum Cholesterol

6. Motion examination for over cyst

7. Urine examination

8. Mantoux test

9. X-ray chest

10. ENT Examinaion

11. Dental Exmaination.

On investigation, if the patients showed evidence of any systemic foci of infection, eg Sinusitis, Dental caries etc, they were treated as advised by the ENT surgeons and Dental surgeons. Whatever the was evidence of worm infestation, deworming was done.

The fundus photographs and fluorescein angiography were done in all the 30 patients. Before injecting fluorescein, test dose was given and pupils were dilated with Tropicamide $1 \%$ and Phenylephrine 10\%. Injection fluorescein sodium $25 \% 3 \mathrm{ml}$, ie $250 \mathrm{mg} / \mathrm{ml}$ was given intravenously and multiple photographs were taken by digital fundus camera and the patterns of CSCR on FFA were observed and notified.

Non recurrent CSCR patient in the primary presentation was then given, systemic antioxidants as Placebo and advised life style modifications and reviewed after 2 weeks and cases which do not resolve at the end of 4 months were subjected to fluorescein angiography to see for any leakage of dye.

In recurrent cases of CSCR, fluorescein angiography is done at the second visit. Angiograph is done earlier in those patients with poor visual acuity at presentation. All patients above 45 years of age were advised fluorescein angiography as a routine and was done earlier for them to rule out choroidal neovascularization.

In cases where leakage of fluorescein was seen, they were subjected to laser photocoagulation and then they were subsequently reviewed after 2 weeks, 3 months and 6 months. 


\section{Results and Discussion:-}

The present study conducted at Regional Institute of Ophthalmology,Govt: Medical college, Thiruvananthapuram during the period january.2018-december 2019.The data drown from clinical observation of 30 cases of central serous retinopathy are discussed below regarding etiological factors, clinical characteristics, pattern on FFA and modality of treatment and recurrence rate.

\section{Incidence:}

The number of cases of Central Serous Retinopathy attending the outpatient department of Regional Institute of Ophthalmology is increasing every year. Thus, it is evident that Central Serous Retinopathy is not a rare disease.

A detailed clinical study was made in 30 cases of Central Serous Retinopathy. These cases in which there was no other ocular pathology except macular oedema. In each of these cases an effort was made to record the patterns of CSCR on fundus fluorescein angiography.

Age:

CSCR shows a great predilection for young adults. Main victims of this disease are from 30-50 years of age. The oldest case is 64 years and the youngest case is 19 years of age with a median age of $30 \mathrm{yrs}$

\begin{tabular}{|l|l|l|}
\hline Age group & No. of patients & Percentage \\
\hline $0-10$ & 0 & 0 \\
\hline $11-20$ & 1 & 3.33 \\
\hline $21-30$ & 1 & 3.33 \\
\hline $31-40$ & 11 & 36.67 \\
\hline $41-50$ & 13 & 43.33 \\
\hline$>51$ & 4 & 13.33 \\
\hline
\end{tabular}

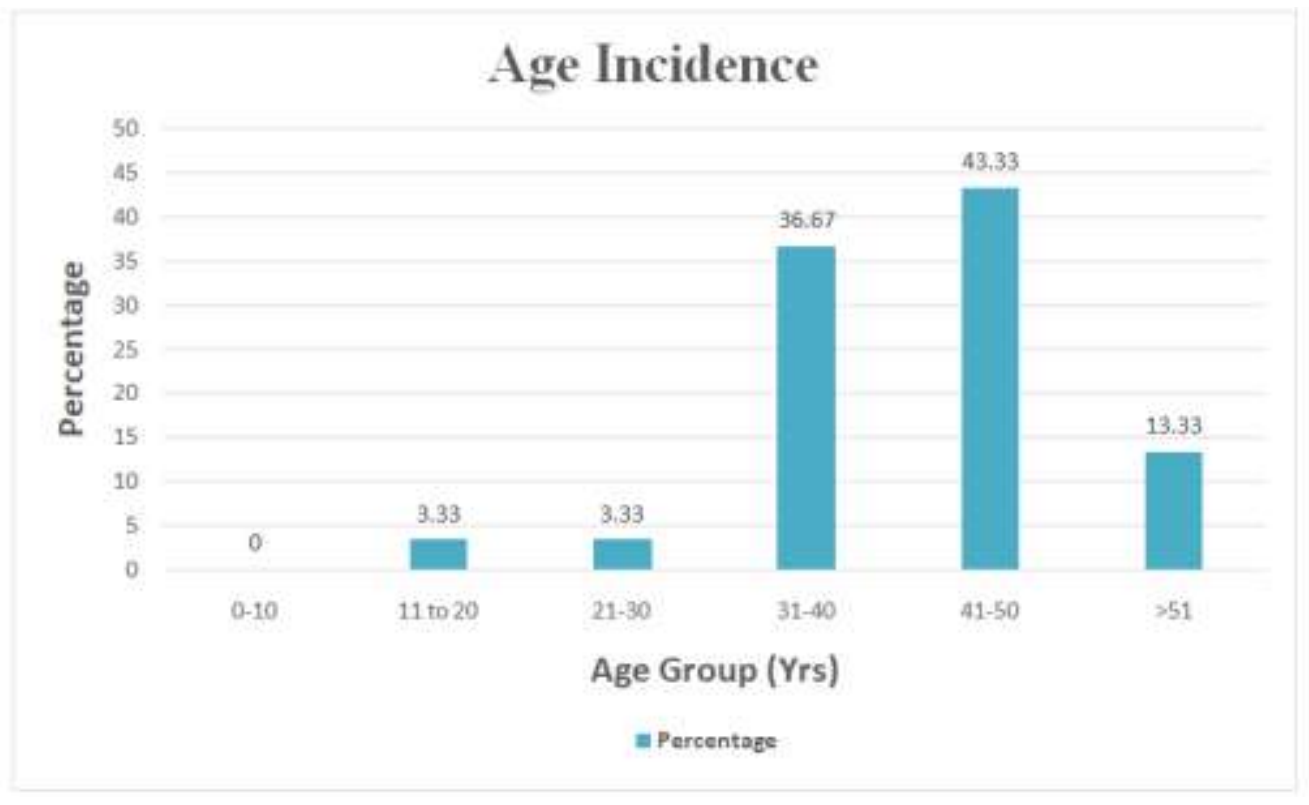

Sex:

CSCR has a prominent predilection for males. Out of 30 cases 22 were male and 8 were females. Male female ratio is approximately $3: 1$.

\begin{tabular}{|l|l|l|}
\hline Sex & No. of cases & Percentage \\
\hline Male & 22 & 73.33 \\
\hline Female & 8 & 26.67 \\
\hline
\end{tabular}




\section{Sex Distribution}

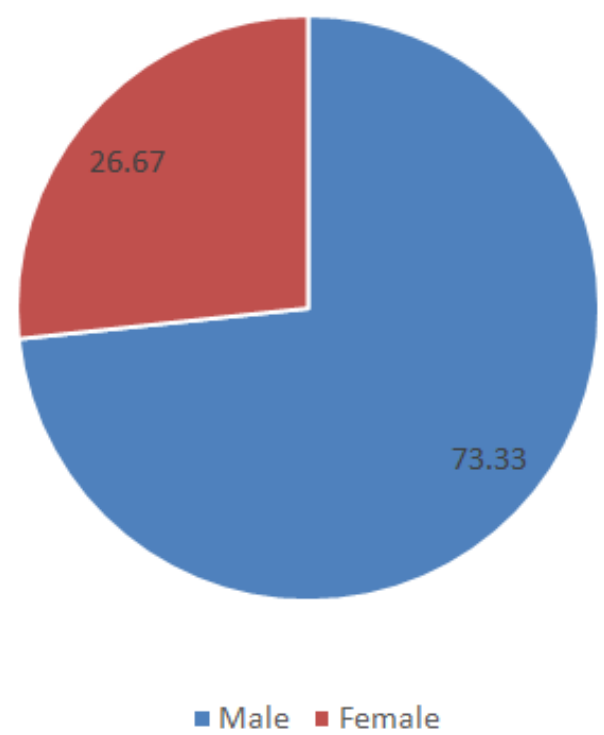

\section{Social status:}

No strata of society are secure from its clutches. In this study, there were cases belonging to all the income groups. Out of 30 cases, 6 were from the low-income strata, 16 cases were from middle class families and 8 cases were from upper class families.

\begin{tabular}{|l|l|l|}
\hline Socio Economic Status & No. of cases & Percentage \\
\hline Low Income & 6 & 20 \\
\hline Middle Income & 16 & 53.33 \\
\hline High Income & 8 & 26.67 \\
\hline
\end{tabular}

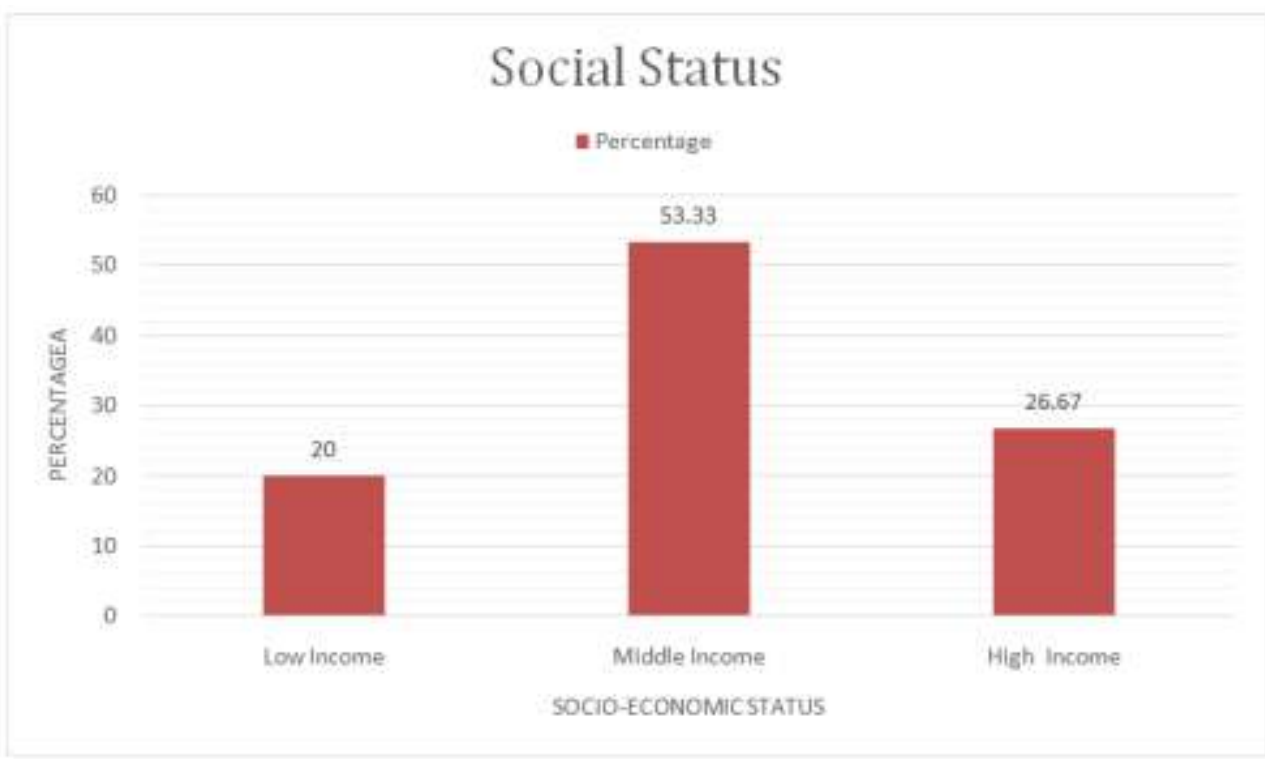




\section{Aetiological study:}

From the results of the investigations done, it is obvious that all victims are relatively healthy. The incidence of Mantoux positivity is 5(16.67\%), Caries teeth 6(20\%), Helminthiasis 1(3.33\%) and Sinusitis 3(10\%).The CSCR is not related to any forms of infection. It is mostly a disease occurring in healthy adults.

\begin{tabular}{|l|l|l|}
\hline Systemic Disease & No. of Cases & Percentage \\
\hline Sinusitis & 3 & 10 \\
\hline Dental Caries & 6 & 20 \\
\hline Mantoux Positivity & 5 & 16.67 \\
\hline Helminthiasis & 1 & 3.33 \\
\hline Diabetes Mellitus & Nil & Nil \\
\hline Hypertension & Nil & Nil \\
\hline
\end{tabular}

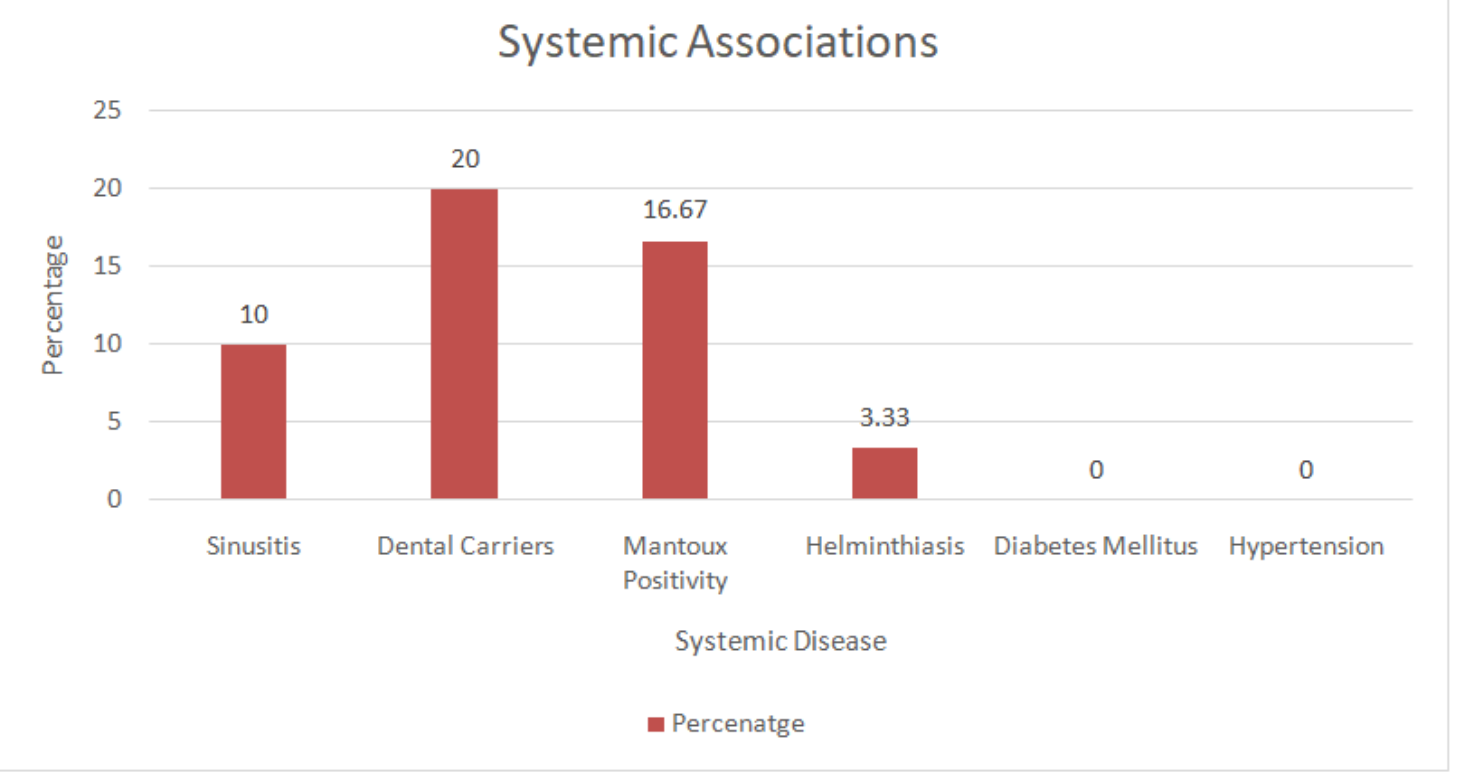

\section{Clinical features:}

Almost all the patients had sudden onset of symptoms. The most common mode of presentation was sudden onset of blurring of vision. Much of the description was as if looking through a cloud or veil. A large percentage also complained of a positive scotoma in the field of vision. A very few numbers of cases complained about metamorphopsia and micropsia.

\begin{tabular}{|l|l|l|}
\hline Nature of Complaint & No. of cases & Percentage \\
\hline Sudden blurring of vision & 26 & 86.67 \\
\hline Positive scotoma & 20 & 66.67 \\
\hline Micropsia & 3 & 10 \\
\hline Metamorphopsia & 8 & 26.67 \\
\hline others & 2 & 6.67 \\
\hline
\end{tabular}




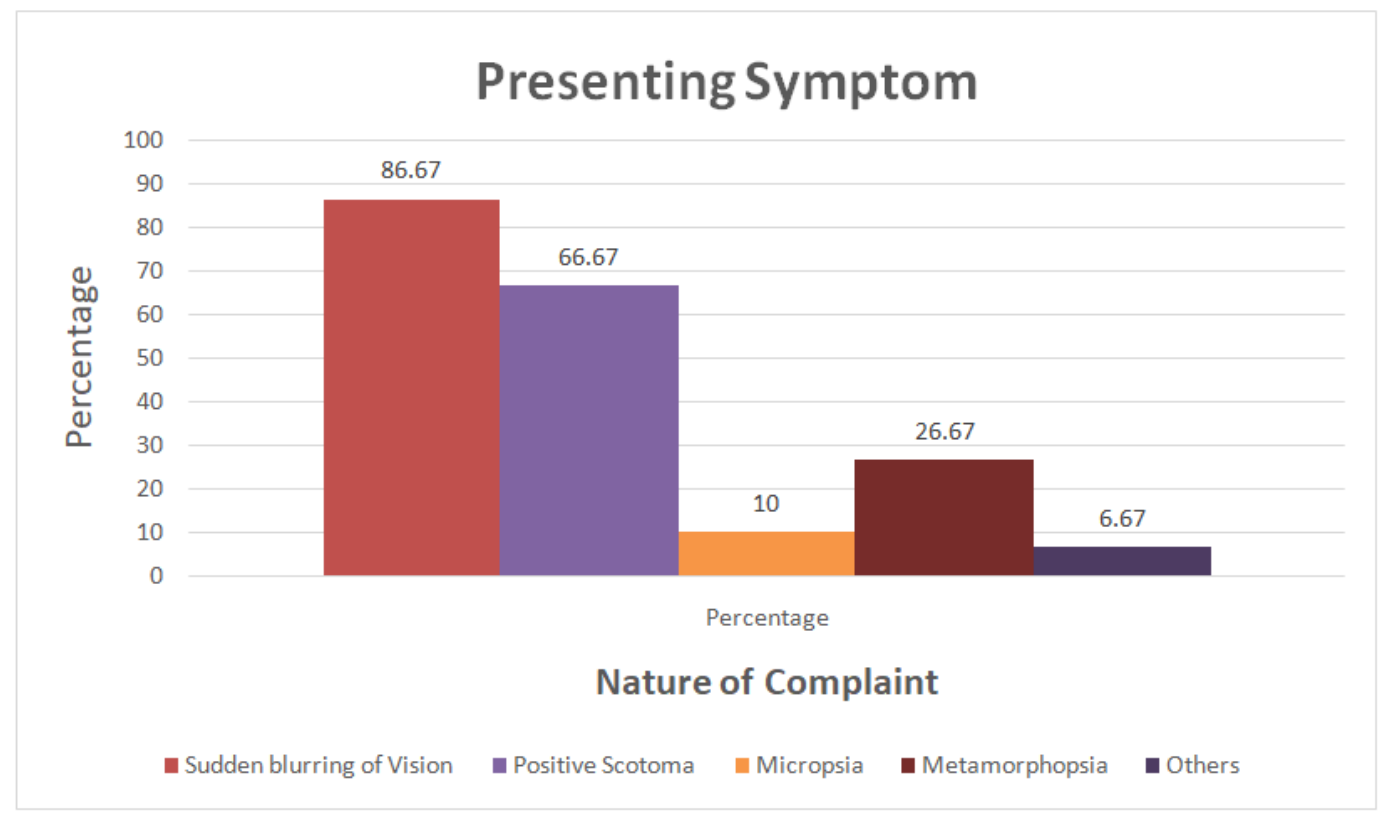

\section{Vision:}

In a majority of cases, visual acuity at the time of presentation was diminished in the range of $6 / 12$ to $6 / 36$. In a few cases, it was between $6 / 9$ and 6/12.

\begin{tabular}{|l|l|l|}
\hline Visual acuity at presentation & No. of cases & Percentage \\
\hline Between $6 / 6-6 / 12$ & 13 & 43.33 \\
\hline Between 6/12-6/36 & 11 & 36.67 \\
\hline Below 6/36 & 6 & 20 \\
\hline
\end{tabular}

\section{Visual acuity at presentattion}

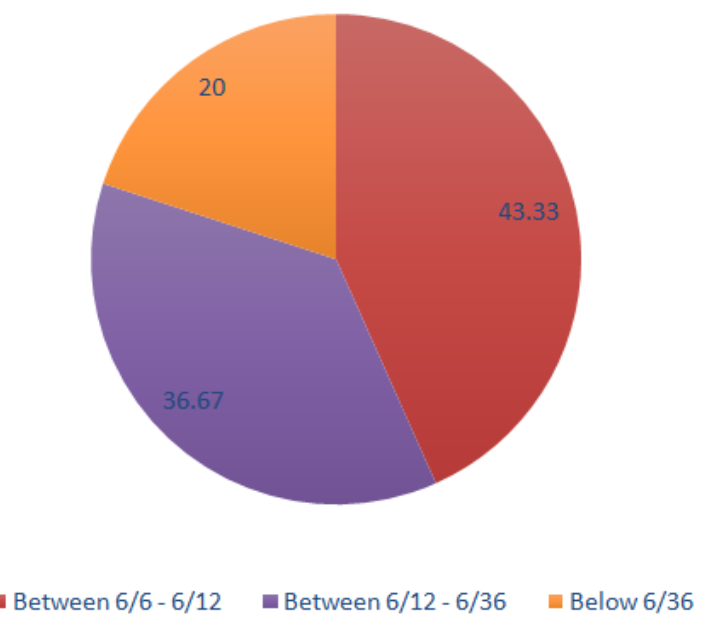

\section{Occupation:}

In this study, there were cases belonging to all the groups. 10 cases were Govt. servants, 6 were house wives, 8 were manual labourers and 6 were others. 


\begin{tabular}{|l|l|l|}
\hline Govt. Servant & 10 & 33.33 \\
\hline House wife & 6 & 20 \\
\hline Manual labour & 8 & 26.67 \\
\hline others & 6 & 20 \\
\hline
\end{tabular}

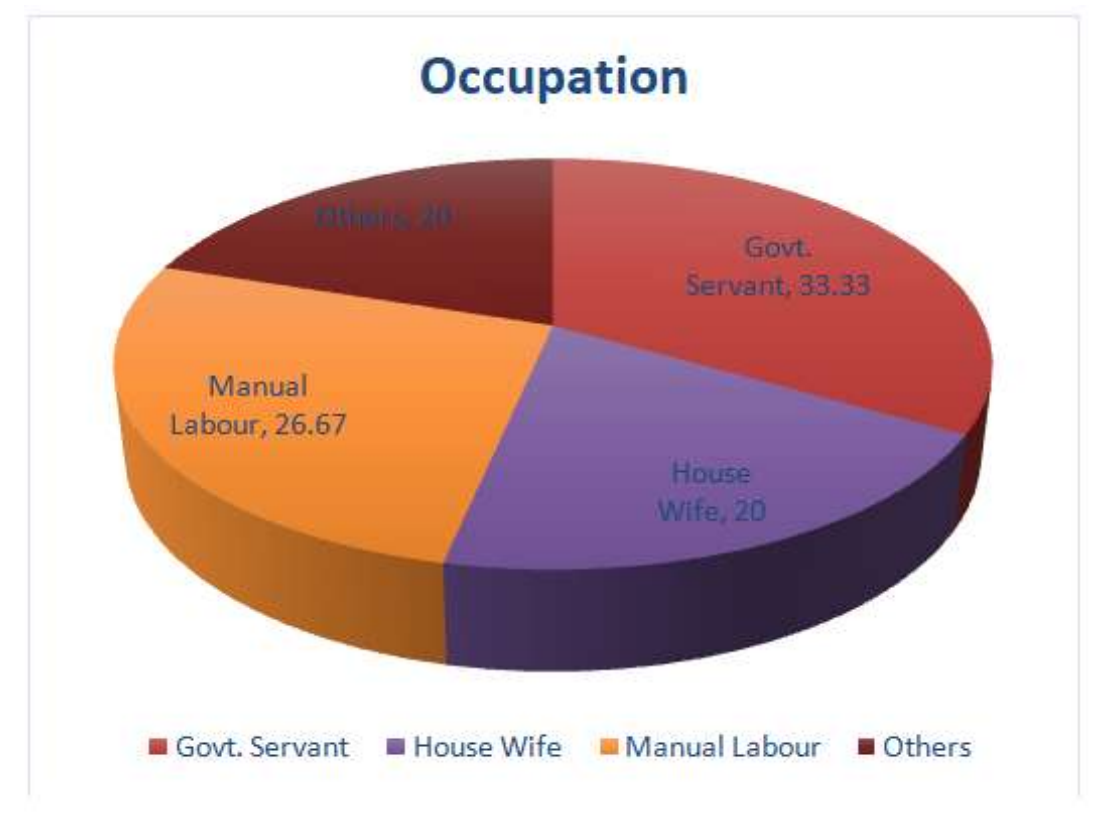

\section{Behavioural Pattern:}

Another striking feature of this study is that in a great majority, out of 30 cases, 22 were Type A personalities, that is $73.33 \%$. only 8 cases (26.67) were controlled persons. This support the fact that the disease is adrenergically conditioned.

\begin{tabular}{|l|l|l|}
\hline BEHAVIOURAL PATTERN & NO. OF CASES & PERCNTAGE \\
\hline Type A Personality & 22 & 73.33 \\
\hline Controlled Personality & 8 & 26.67 \\
\hline
\end{tabular}

\section{Behavioral Pattern of Patient}

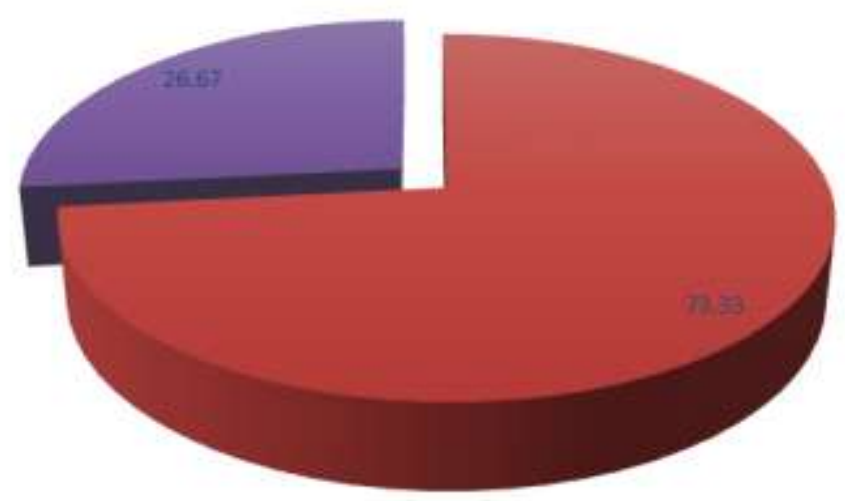




\section{Eye involvement:}

In this study, the majority of cases were unilateral. In 28 out of 30 cases, the disease was unilateral (93.33\%). Simultaneous bilateral involvement in CSCR is rare, but was seen in 2 out of 30 cases (6.67\%).

\begin{tabular}{|l|l|l|}
\hline Eye Involvemnt & No. Of cases & Percentage \\
\hline Unilateral & 28 & 93.33 \\
\hline Bilateral & 2 & 6.67 \\
\hline
\end{tabular}

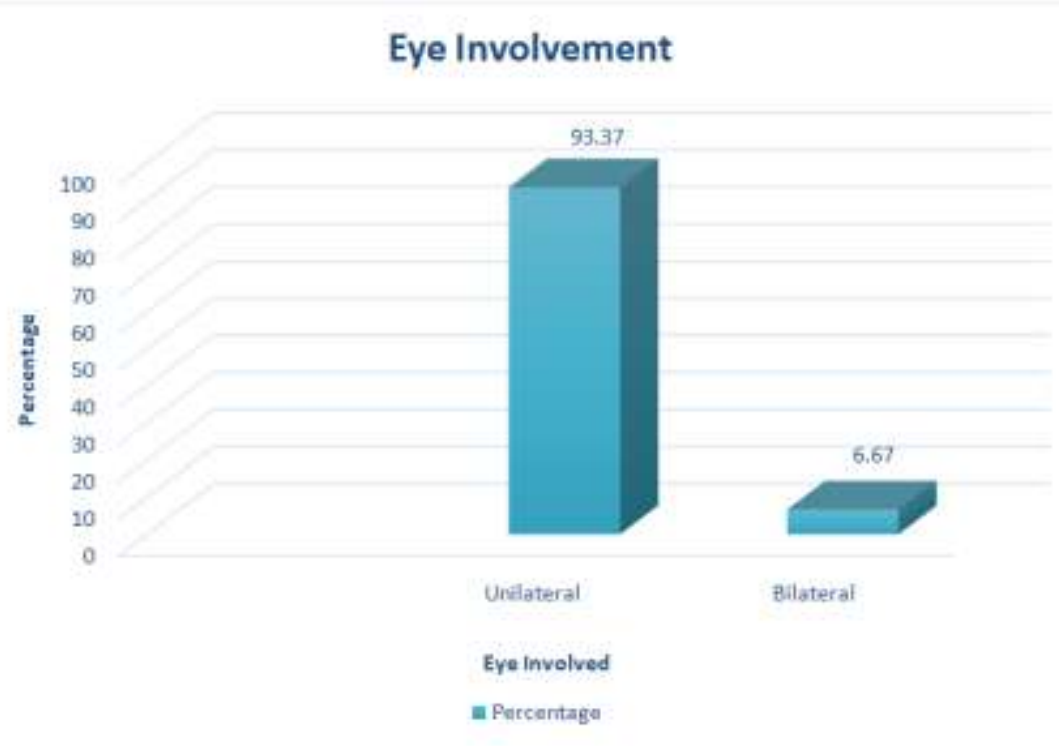

FFA Pattern:

In this study, $60 \%$ of cases shown Ink blot pattern of leak (18 cases out of 30). No active leak is seen in $30 \%$ of cases. Smoke stack was 2(6.67\%). Diffuse leak seen in 1 case (3.33\%).

\begin{tabular}{|l|l|l|}
\hline Pattern of leak & No. of cases & Percentage \\
\hline Ink Blot leak & 18 & 60 \\
\hline Smoke Stack leak & 2 & 6.67 \\
\hline Diffuse leak & 1 & 3.33 \\
\hline No active leak & 9 & 30 \\
\hline
\end{tabular}

\section{FFA Pattern}

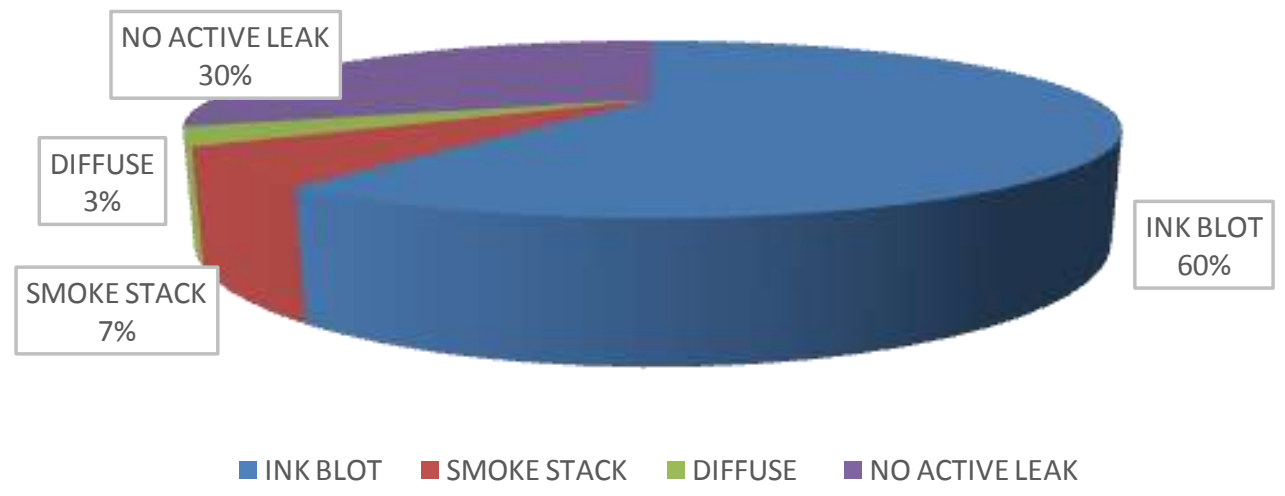




\section{Modality of Treatment:}

In this study Laser photocoagulation done in 14(46.67\%) cases. 16(53.33) cases undergone placebo treatment (......... and Systemic antioxidants).

\begin{tabular}{|l|l|l|}
\hline Treatment & No. of cases & Percentage \\
\hline Laser Photocoagulation & 14 & 46.67 \\
\hline Placebo & 16 & 53.33 \\
\hline
\end{tabular}

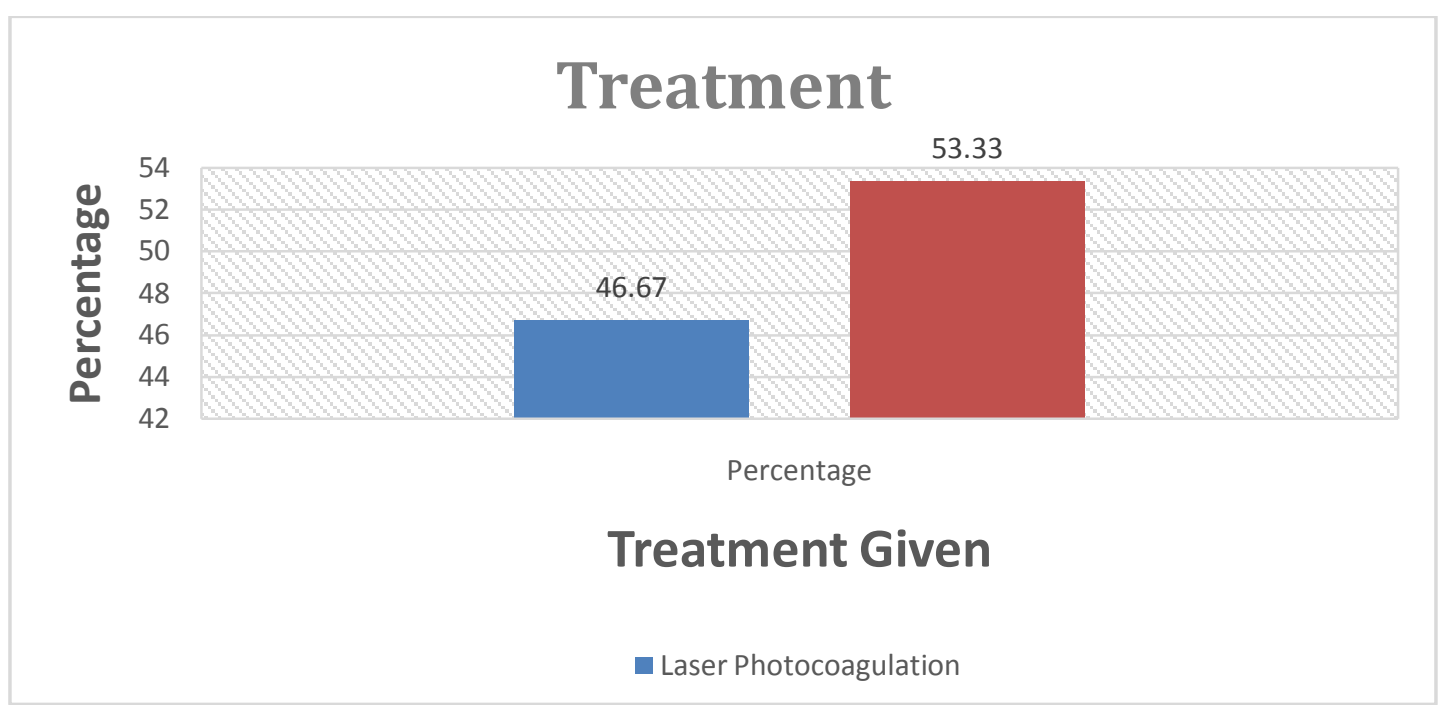

\section{Diagnosis:}

Diagnosis was made on the basis of clinical examination of fundus. In patients coming to Ophthalmic department with the complaints of positive scotoma or sudden blurring of vision. Proper examination of the fundus was carried out after full dilatation of pupil. Media was clear in all cases.

There was a circumscribed oedema in the macular and paramacular areas. In a few cases, the oedema extended slightly beyond the macula. The area of oedema showed a greyish elevated appearance and the oedematous area was sharply demarcated from the surrounding retina by shining, bright ring reflex. In some cases, the area of the oedema showed yellowish white dots in the centre. Foveal reflex was absent in all cases.

On Fundus fluorescein angiography, Ink blot, smoke stack, diffuse pattern of leaks was seen. Some of the cases were shown no active leak. Majority of the leaks were Ink blot pattern.

The periphery of the retina was normal in all cases. Thus, the diagnosis was determined on the basis of complaints, retinal oedema confined to macular and paramacular regions, absence of trauma and other changes in the fundus.

\section{Summary and Conclusion:-}

A wide variety of explanations have been proposed regarding the aetiology of the disease and its final visual outcome. But an attempt has been made in this study to thoroughly investigate and analyze 30 cases of Central Serous Retinopathy with a view to throw some light on the various patterns of leak on fundus fluorescein angiography. Fundus fluorescein angiography (FFA) plays a crucial role in the understanding of different disease processes affecting the eye. A good knowledge of the changes occurring in the fluorescein angiogram is importantfor correct diagnosis and management of eye disorders. It is noted that OCT cannot predate any pathognomonic changes in CSCR. Sequential OCTs can only show the status of neurosensory and RPE detachments whereas FFA not only confirms the diagnosis but also helps in ruling out conditions that mimic CSCR, such as choroidal tumors and CNV that is not benign as CSCR. 
CSCR shows in undoubtedly high preponderance in males. Of the 30 cases evaluated in this study, 22 were males, ie the incidence is $73 \%$ in males and $33 \%$ in females. The age group affected was mainly in the age group of 20-50 years. So $20-50$ age group undoubtedly shows a high incidence of $80 \%$.

Except for 2 cases, all the 28 cases out of the 30 cases analysed were unilateral. 2 cases were bilateral. Thus unilateral presentation is noted to be the main mode of presentation (93\%).

Most of the cases evaluated were in the visual acuity range of $6 / 6$ to $6 / 12$. Out of 30 cases, 13 cases had visual acuity in the range of $6 / 6-6 / 12(43 \%)$. 11 cases had vision in the range of $6 / 12-6 / 36(37 \%)$ and 6 cases had below $6 / 36$ vision.

Fundus examination on presentation showed findings typical of CSCR. Few patients had minute hemorrhages in the area of RPE detachment. A few patients did not show the typical ring reflex around the detachment.

On fundus fluorescein angiography, Ink blot pattern of leak is seen in 18 patients out of 30 cases (60\%). FFA did not show any specific leak in 9 patients $(30 \%)$. Smoke stack pattern of leak seen in 2 cases(6.67\%). Diffuse leak seen in 1 patient $(3.33 \%)$. It demonstrates that Ink blot pattern of leak is more frequent than smoke stack pattern appearance.Usually, one or two leakage points are seen. The site of leakage is often hypopigmented, showing transmission of choroidal fluorescence. The hypopigmentation of the RPE is not associated with choriocapillaris atrophy or geographic atrophy of the RPE. Most leakage points are located within 2-disc diameters from the temporal fovea. Less than $10 \%$ of cases demonstrate leakage in the foveal area. The most common location of leakage points is the superonasal quadrant of the posterior pole. In other cases of CSCR, multiple distinct foci of hyperfluorescence are present, yet none of them demonstrate expanding fluorescence (minimally enlarging spot configuration). Finally, some cases show partial confluence of multiple irregularly distributed patches of hypopigmentation (multifocal ink-blot-like leakage). Kanski has reported that smoke-stack appearance is more common than ink-blot, whereas other studies by Baig, Peykan and their colleagues have reported ink-blot appearance more commonly seen in CSCR on FFA than smoke-stack appearance.

In this study another striking feature is that majority of cases (73\%) were Type A personalities. Only $27 \%$ were in the controlled group. This supports the fact that the disease is adrenergically conditioned.

In this study, there were cases belonging to all the income groups. Out of 30 cases, 6 were from the low-income strata, 16 cases were from middle class families and 8 cases were from upper class families.

The most common mode of presentation was sudden onset of blurring of vision. Much of the description was as if looking through a cloud or veil. A large percentage also complained of a positive scotoma in the field of vision. A very few number of cases complained about metamorphopsia and micropsia.

Probing into the aetiology, Dental caries was detected in 6 patients, sinusitis was seen in 3 pateints, 5 patients showed mantoux positivity, the stool xamination in 1 pateint showd ova for round worms.

Placebo treatment was given in 16 cases, and 14 cases were taken up for laser photocoagulation.

Thus, CSCR is a relatively common, benign and self-limiting disorder with most cases resolving spontaneously over a period of 3-4months 


\section{Review of Literature and References:-}

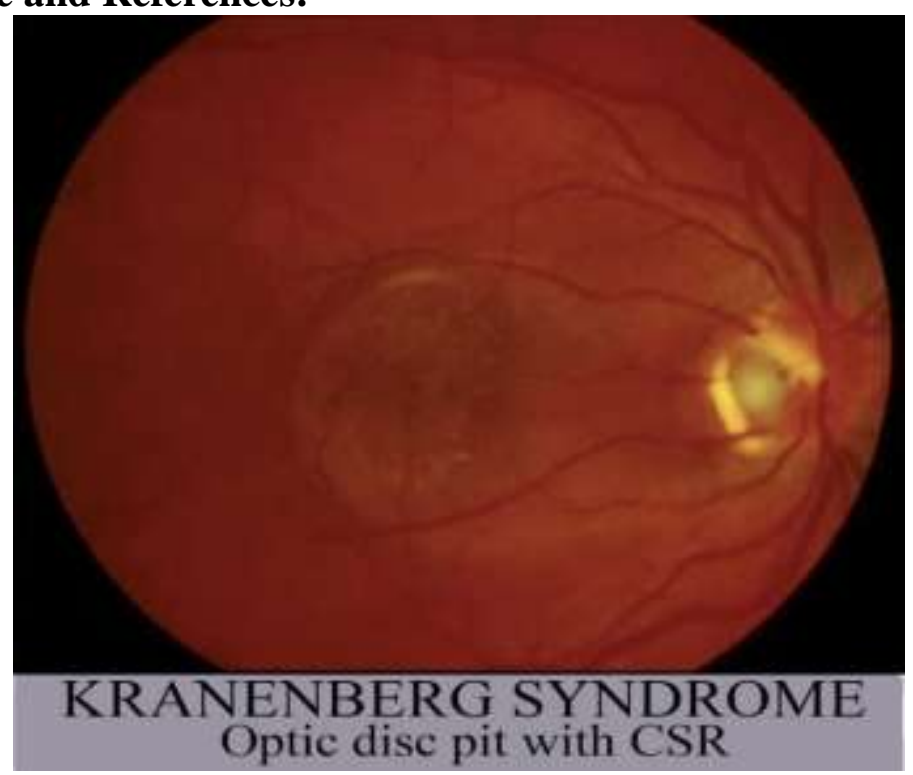

\section{Pathogenesis:}

The pathophysiological event leading to neurosensory retinaldetachment remains unknown. Most researchers believe that stasis, inflammation or a combination of the above factors leads to abnormal permeability of the inner chorio capillaries and eventful elevation of RPE and serous retinal detachment. Yet the presence of these pathologic mechanisms in the choroid still cannot replicate the constellation of findings in this disorder. In the acute form of the disease, many believe that there is a disruption in the continuity of the detached RPE, leading to focal leakage beneath an overlying neurosensory retinal detachment, the signature of the disorder. This form of mechanical alteration in the integrity of the RPE, referred to as a blow -out or micro rip, alters its normally impermeable stable leading to serous detachment of retina. In this sense, the retina seems to be affected secondarily; whereas inner choroidal changes represent the primary abnormality of the disorder, leading to current designation of the disease as CSCR. The primary exudative disturbance in the inner choroid, resulting in macular detachment is thought to be non-vasogenic that is not associated with proliferation of choroidal vessels. The initial avascular nature of CSCR distinguishes it from other forms of macular detachment associate with neovascularization of the choroid and eventual disciform scarring.

The pathogenesis of CSCR may be summarized in the following chart.

\section{Increased choroidal hyper permeability}

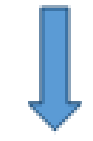

Increased sub RPE fluid pressure

Focal dysfunction of RPE pump

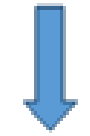

Neurosensory detachment of overlying retina 


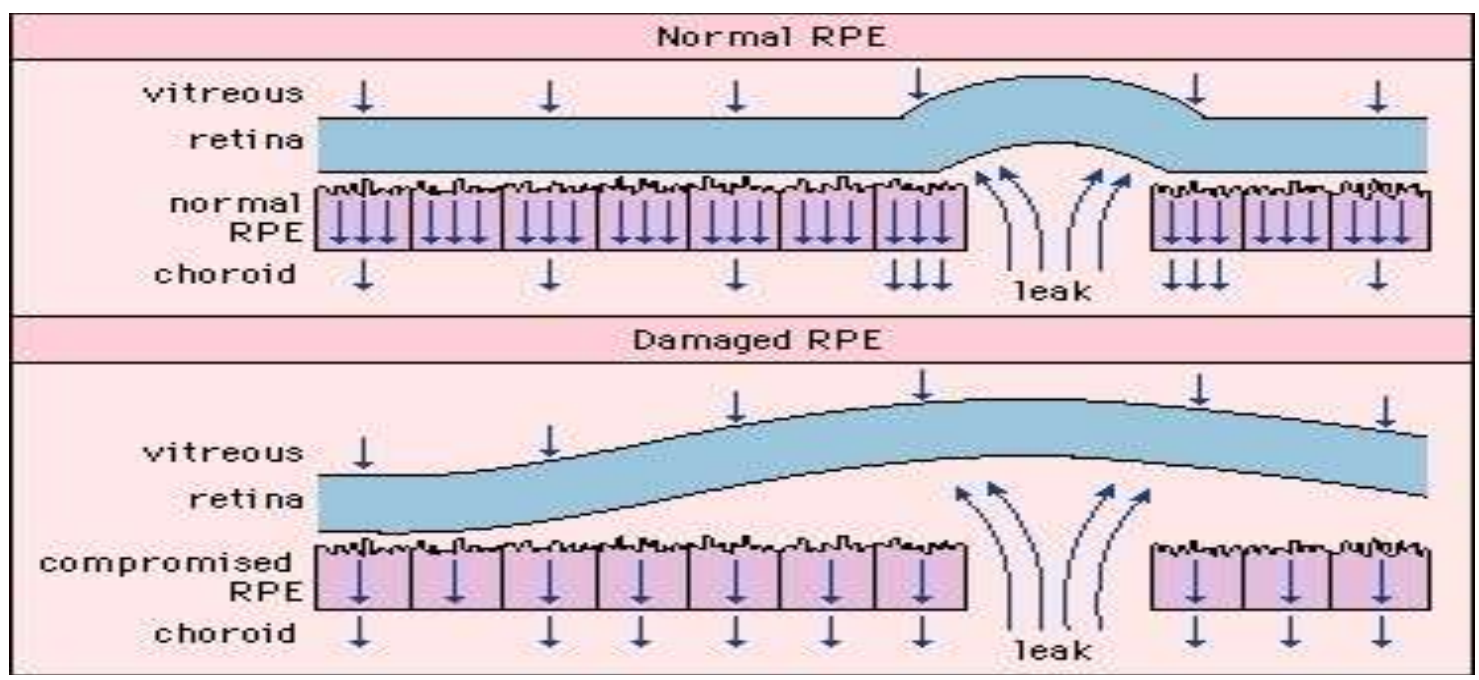

The reason why the oedema is confined to the macular region is explained by the fact that the thick fibre layer of Henle can absorb large quantities of fluid. The avascularity of the foveal avascular zone helps in the formation of oedema as the absence of capillaries will retard absorption. Both choroid and retina are involved in the changes and this can be detected by the pigmentary disturbances in the macular area.

In addition to the serous detachment of sensory retina, three abnormalities were noted in the pigment epithelium and bruch's membrane. Drusen like structures were felt to correspond to stationary, well dermacatal fluorescent spots. Spindle like seperations were found between the cuticular and elastic portions of bruch's membrane, possibly corresponding to the slowly enlarging round spots of fluorescein accumulation. Holes were found in the cuticular portions of Bruch's membrane which might result in rapid inward diffusion of fluorescein beneath the retina as seen in the vertical type of leak.

At the early stage of the disease, the entire changes are reversible. No permanent anatomical or functional changes results if the fluid is fully absorbed. This will result in subsequent restoration of full vision. However, sometimes the exudative process may recur repeatedly and may result in cumulative damage.

With each recurrence, there is increasing risk of some permanent visual impairment. When the lesion persists for some time, subtle changes occur and some of these changes are irreversible. The retinal pigmentary epithelium becomes raged and the cells become les densely pigmented. There may be patchy and uneven thickening of Bruch's membrane and early drusen may be seen at some sites. Focal proliferation of pigment epithelium may also be seen.

Within the retina, the early irreversible changes are manifested by loss of cell nuclei in the outer nuclear layer and this is clearly seen at or near the fovea. There is rarefaction of the outer plexiform layer. When the process is more advanced, loss of light receptor cells is more marked and cystoid changes within the outer plexiform layer become more prominent. This generally reflects the severity of the cell loss.

The choroid also shows some changes. The walls of the chorio-capillaries may become thickened. In some cases, there is apparent reduction in the capillary lumen. During late stages, the thickened and somewhat distorted retina is adherent to a varying degree to the irregular pigment epithelium and Bruch's membrane. There is evident loss of light receptor cells and in some cases this layer may be completely destroyed.

\section{Stages of csr:}

Acute:

Patients are asymptomatic as there is no break in diffusion barrier.

Sub Acute:

As the acute stage of disease progresses some patients develop focal breaks in the tight junction of the RPE cells. 


\section{Chronic:}

The leaking through the break of tight junction become chronic; a field defect will develop which often involves fovea resulting marked decrease in visual acuity.

\section{Inactive:}

Most of the patients in this stage have no history of previous eye problem. The had asymptomatic stage and spontaneously improve.

\section{Late Complications:}

Sub retinal neo vascularization develops which is seen 5 to 10 years after the first diagnosis of CSR. Sub retinal neo vascularization is of two types on fluorescein angiography

1. Typical (one or two leaking areas on FFA)

2. Atypical (Multiple leaks are seen on FFA)

\section{Clinical Charactrestics:}

Incidence:

CSCR is a sporadic, self-limiting disease of young or middle-aged adult males. The ratio of male to female now reports is $8: 1$. The age incidence is mainly confined to the group between 20 and 45 years. The disease occurs in all socio-economic strata equally. CSR is commonly found to occur in Type A personalities.

\section{Symptoms:}

The onset of disease is usually sudden. Patient do not notice any associated general illness. Many patients first notice a minor blurring of vision, followed by;

1. Metamorphopsia (defective distorted vision)

2. Micropsia (distorted visual perception in which objects appear smaller than their actual size)

3. Chromatopsia (visual defect in which objects appear unnaturally coloured)

4. Central scotoma

5. Increasing hyperopia

6. Reduced contrast sensitivity

\section{Visual Acuity:}

Most of the cases have $6 / 6$ or $6 / 9$ vision in the early stages. Some may present with $6 / 12$ or $6 / 24$ vision. The vision in most cases improves with a plus lens, as the foveal portion of the retina is elevated from the surface. There will be difference between the subjective and objective refraction of the eye.

Micropsia is probably caused by separation of receptor elements which occurs as the retina becomes displaced and bowed forward by the sub retinal fluid. In effect the cones are stretched apart causing retinal images to fall on fewer receptors than normal, thus the object appears smaller than it actually is.

The black spot that many patients experience in front of their visual field is termed positive central scotoma. By definition a positive scotoma is a field defect which is projected into space and into conscious awareness. The positive scotoma in CSR can be seen in the dark with the eyes closed and it is reinforced by blinking. It appears darker on a lighter background than in a dark background.

Metamorphopsia occurs and is demonstrated by Amsler grid. Many patients will notice distortion of straight lines on ruled paper. This visual defect can be explained by the mechanical alterations in the usual alignment of receptor cells in the retina which is bowed anteriorly.

Rarely, impaired colour vision is noticed only if fluid accumulates in the central macular area. Alterations of colour vision are detectable on standard testing. Eg: Ishihara plates

\section{Fundus Appearance:}

The fundus appearance of the lesion is almost always diagnostic. Ophthalmoscopically seen:

1. Elevation of macular area.

2. A circular ring reflex on the retina

3. A round or ovoid blister like sensory retinal detachment of various sizes 
4. Foveal reflex is absent or distorted

5. After few weeks of onset of the disease, tiny irregular white or yellow precipitates become deposited on the retina

6. Atrophic RPE changes

7. In chronic cases, a fine brown and white pigment epithelial scar will develop.

8. Extra macular RPE tracts.

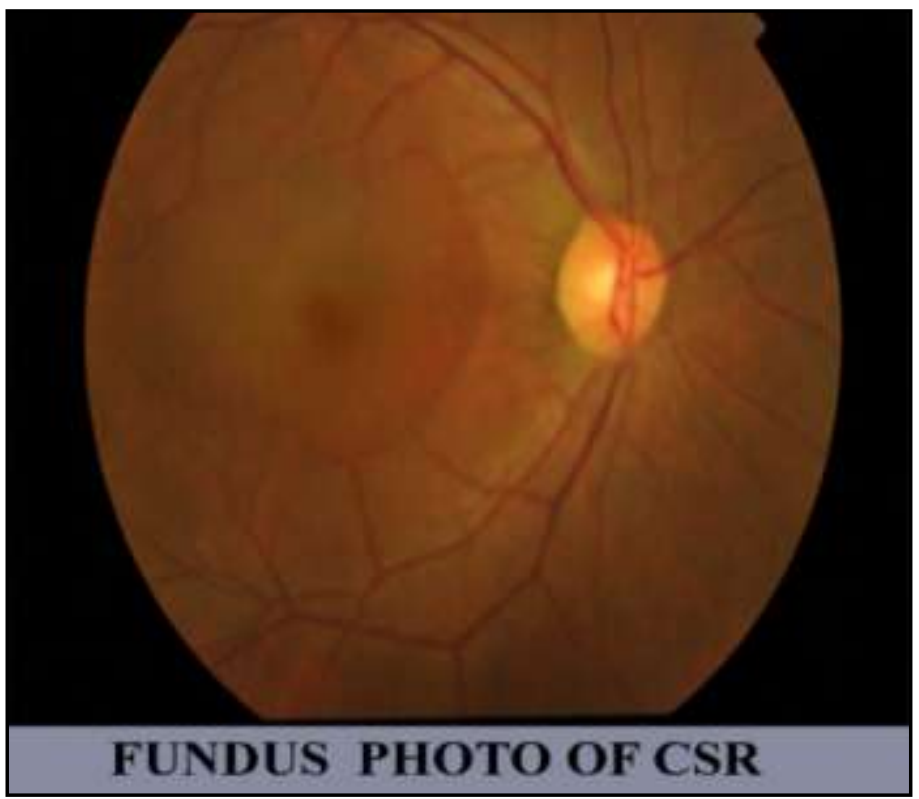

Slit lamp examination shows diffuse retinal oedema and a displacement of the rounded contour of the internal limiting membrane towards the observer. Careful slit lamp examination aided by stereo photography indicates focal serous or hemorrhagic elevations of pigment epithelium.

\section{Diagnostic Tests:}

\section{Visual Acuity:}

Visual acuity is usually only modestly reduced (6/9 to 6/12) and in many cases can be corrected to 6/6 with the addition of a weak plus lens. The elevation of sensory retina gives rise to the acquired hypermetropia and there is disparity between the subjective and objective refraction of the eye.

\section{Amsler grid test:}

Amsler grid evaluates the central 20-degree visual field or 10-degree visual field from the point of central fixation. There are seven charts which come in the Amsler grid series. A $10 \mathrm{~mm}$ square is divided into smaller $5 \mathrm{~mm}$ squares when it is viewed at $33 \mathrm{~cm}$ each small square subtends an angle of 1 degree. The most useful charts are No.1, No.2 and No.6. No.6 has a finer grid and is more sensitive than chart No.1.

The patient was reading spectacles and one eye is covered. With the uncovered eye he is instructed to look at the central dot of the Amsler grid and he is asked to verbalize the subjective defects or to reproduce on paper any distortion, wavy lines, blurred areas or blank spots anywhere on the grid. In CSR patients reports that the lines are wavy. 


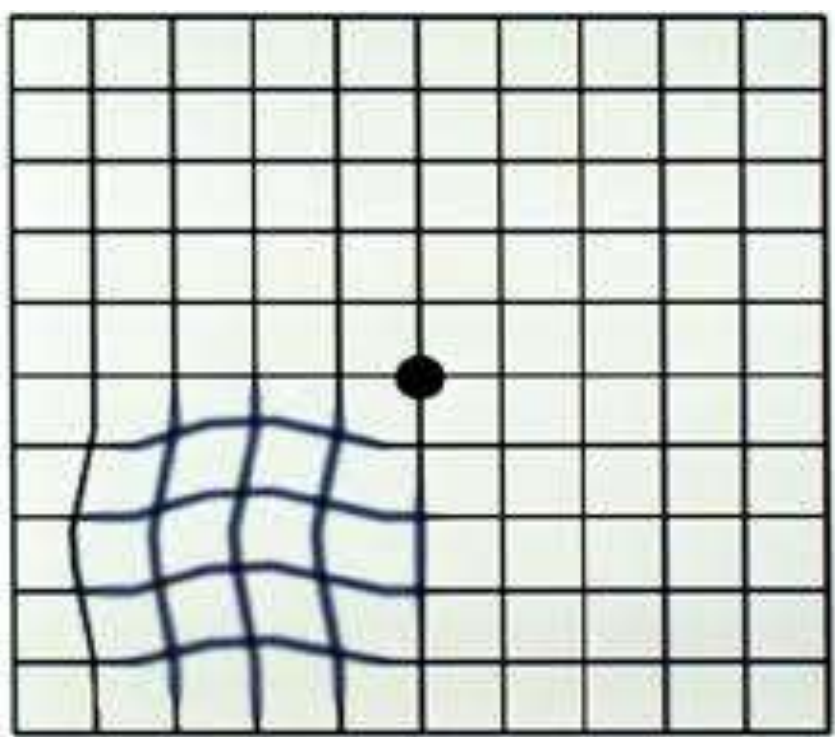

\section{Central visual fields:}

Although the merits of Amsler grid charting as a test for documenting the nature of central field changes in patients with central serous retinopathy are recognized, the value of this technique in detecting defects in retinal function after oedema fluid has absorbed is less well established. It has been reported that static perimetry investigations, however continue to reveal abnormal profiles in a high proportion of patients with resolved retinopathy. Static perimetry results show scotomatous defects close to fixation.

Pattern standard deviation as calculated by Humphrey 10-2 automated static perimetry at presentation showing bilateral paracentral scotoma.
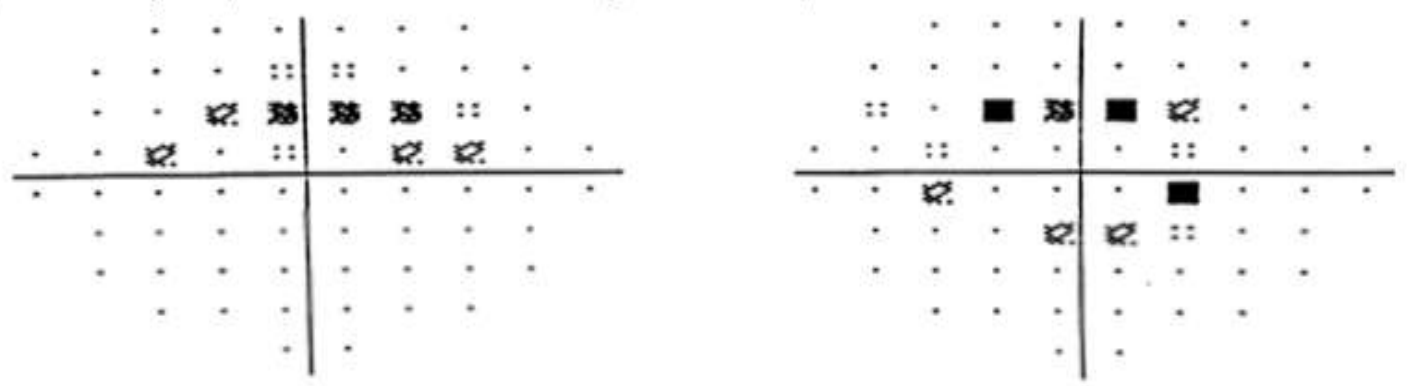

\section{Follow up visual fields 10 months after treatment showing partial} resolution of scotoma.
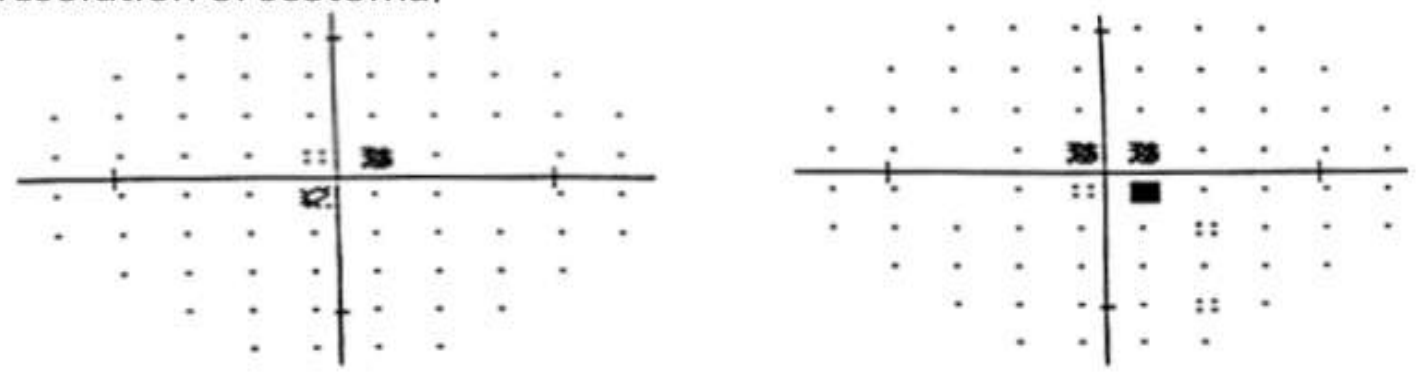

D.Photostress test: This is useful in diagnosis when ophthalmoscopy is equivocal. There is impairment of visual acuity following stimulation of the affected macula by a bright light. The best corrected visual acuity is first determined. Then a bright torch light is held about $3 \mathrm{~cm}$ away from the patient for 10 seconds and the patient fixes his eye on light. Then the photo stress recovery time (PSRT) is determined by the time taken for the patient to read any three letters of the pretest acuity line. Normally it is 5-30 seconds. In CSR it is much prolonged. 


\section{Dark adaptation:}

There is no predictive value for this test. But few patients with CSR showed a delay in the transition from photopic to scotopic vision.

\section{Colour vision tests:}

Colour vision is usually impaired and patients shows blue-yellow defects. This can be demonstrated by standard Ishihara charts.

\section{Slit beam sign:}

Watzke and Allen described that when macula is illuminated by a narrow beam of the slit lamp and viewed through a Hruby or fundus contact lens, the beam showed a gentle bowing towards the observer in cases of CSR. The degree of bowing was dependent on the retinal elevation.

\section{Multifocal Electroretinogram:}

A study using multifocal electro retinography indicated that the height of serous macular detachment in CSR correlated with the impairment in the conduction of electrical responses in the paracentral macula (by measurement of N1 and P1 latencies). A topographical analysis of the multifocal ERG is useful in the clinical observation of CSCR.

\section{Special invesigations:}

Today current multimode imaging technology is helpful in the evaluation of a patient.

\section{Fundus fluorescein angiography:}

Fundus fluorescein angiography (FFA) is technique for examining the circulation of retina and choroid using a fluorescent dye and a specialized camera. It involves the injection of sodium fluorescein into systemic circulation, and then an angiogram is obtained by photographing the fluorescence emitted after the illumination of retina with blue light at a wavelength of $490 \mathrm{~nm}$. The test uses the eye tracing method. The fluorescein dye also reappears in the patient's urine, causing the urine to appear darker, or sometimes orange. It can also cause discoloration of the saliva.

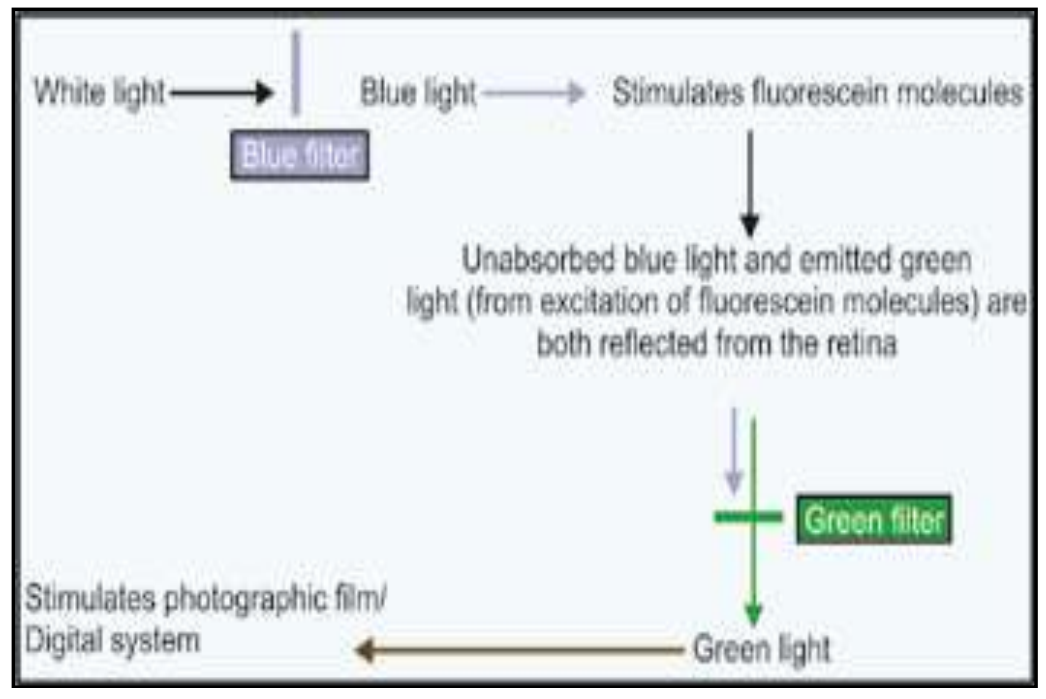

FFA helps in confirming the diagnosis of CSCR. FFA provides three main informations

1. The flow characteristics in the blood vessels as the dye reaches and circulates through the retina and choroid.

2. It records fine details of the pigment epithelium and retinal circulation that may not otherwise be visible.

3. Gives a clear picture of the retinal vessels and assessment of their functional integrity.

FFA can demonstrate unifocal or multifocal areas of smoke-stack, ink blot or diffuse pattern of leaks. Subtle RPE detachments may become obvious and retinal pigment anomalies which may be far more than clinically detected; can be demonstrated with this investigation. This also helps the clinician to locate the area of leak for treatment. 


\section{Sodium fluorescent:}

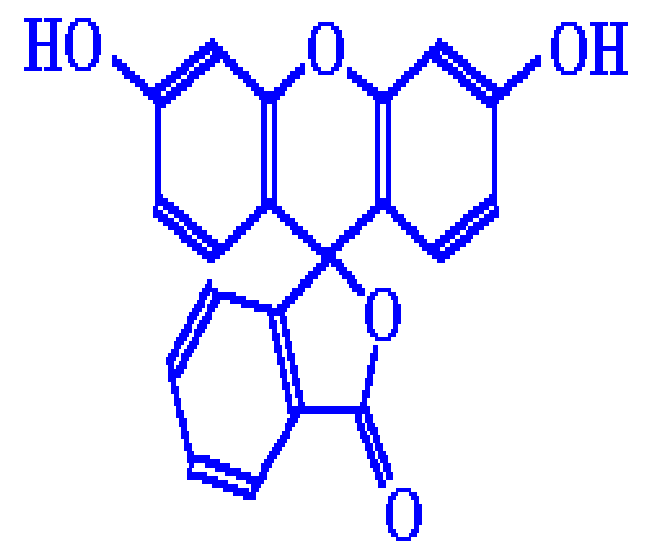

Sodium fluorescein is an organic dye. It has a molecular weight of 376 Daltons, and is $80 \%$ bound to plasma albumin. The remaining $20 \%$ is seen during angiography. The dye absorbs light in the blue range of the visible spectrum, with absorption peaking at $490 \mathrm{~nm}$ (blue). It emits light at $530 \mathrm{~nm}$ (yellow). It is metabolized by the liver and excreted by the kidneys., most dye is cleared within 24 hours.

\section{Equipment:}

1. Exciter Filter: Allows only blue light to illuminate the retina. Depending on the specific filter, excitation wavelength hitting the retina will be between $465-490 \mathrm{~nm}$, most only allow light through at a wavelength of 490nm.

2. Barrier Filter: Allows only yellow-green light (from the fluorescence) to reach the camera. Both filters are interference band pass filters, which means they block out all light except that at a specific wavelength. The barrier filter only allows light with a wavelength of $525 \mathrm{~nm}$, but depending on the filter, it can be anywhere from $520-530 \mathrm{~nm}$.

3. Fundus Camera: Either digital or with camera body containing black and white, or slide positive film.

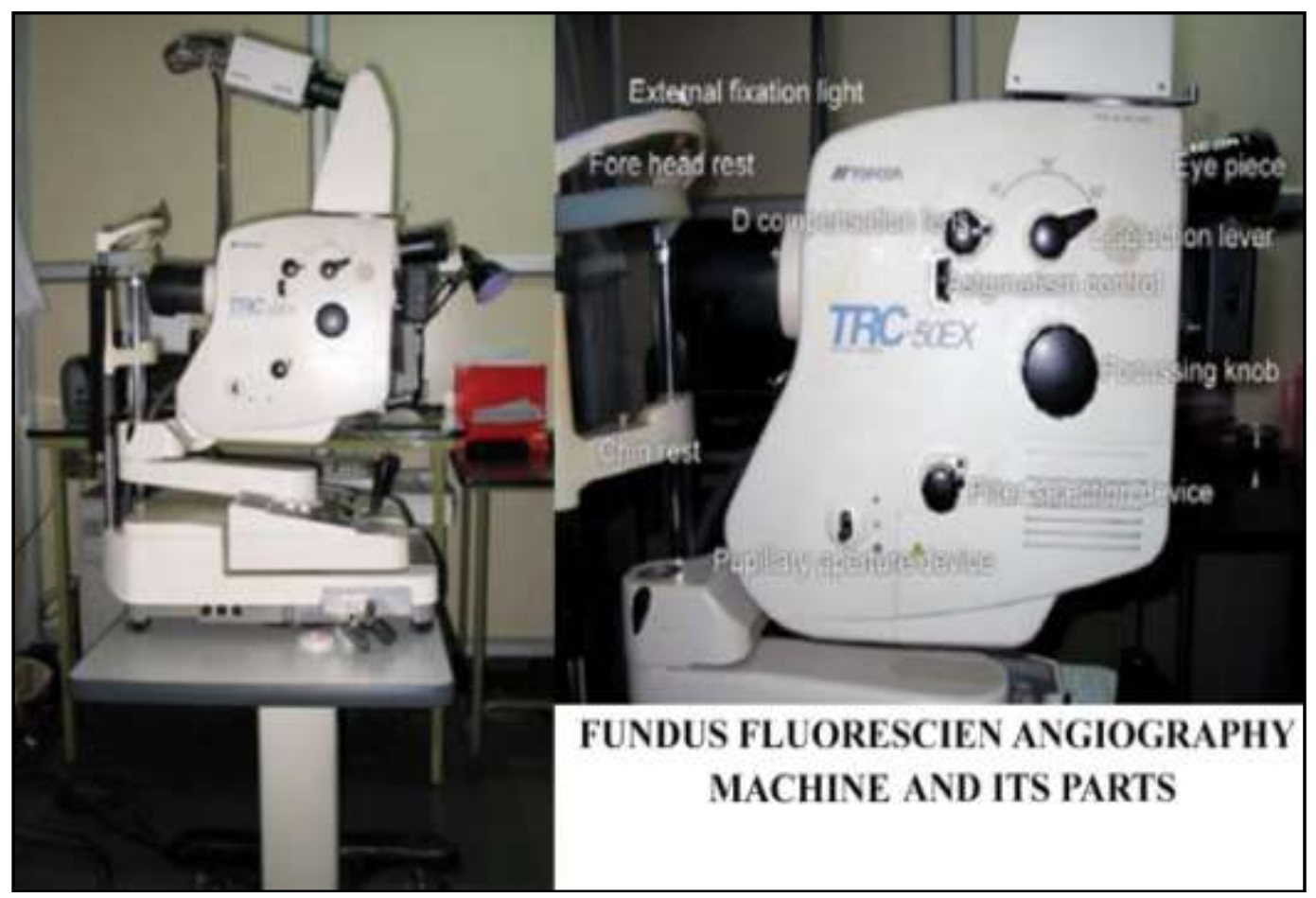


Fluorescence Angiography in Cscr:

In the early phase there is an attenuation of choroidal fluorescence by subretinal fluid. Then the fluorescence enters the subretinal space either as a vertical stream (smoke stack) during late venous phase.

Then the dye spreads laterally taking on a mushroom or umbrella configuration until the entire area of detachment is filled.

\section{Ink blot appearance:}

Occurs occasionally when the initial hyperfluorescent spot gradually increases in size until the entire subretinal space is filled.

In some cases, as the smoke stack ascends it may spread evenly and centrifugally. With chronic disease or with increased number of recurrences, the only consistent feature is increased prevalence of diffuse leakage. Historically fluorescein angiographic leak in CSR was $1^{\text {st }}$ reported by Maumenee in 1965. The classic smoke stack leak was described in 1971 by Shimzu and Toari Spitnaz in 1980. Subsequently classified CSR into three types based on the fluorescein angiographic features.

\section{Type 1:}

Typical leak with no RPE detachment

Type 2:

Typical leak with RPE detachment

\section{Type 3:}

Serous detachment with no leak, but with pressure of RPE detachment.

Inverse smoke stack can occur rarely.

Multifocal leak can up to 2-7 leakage points.
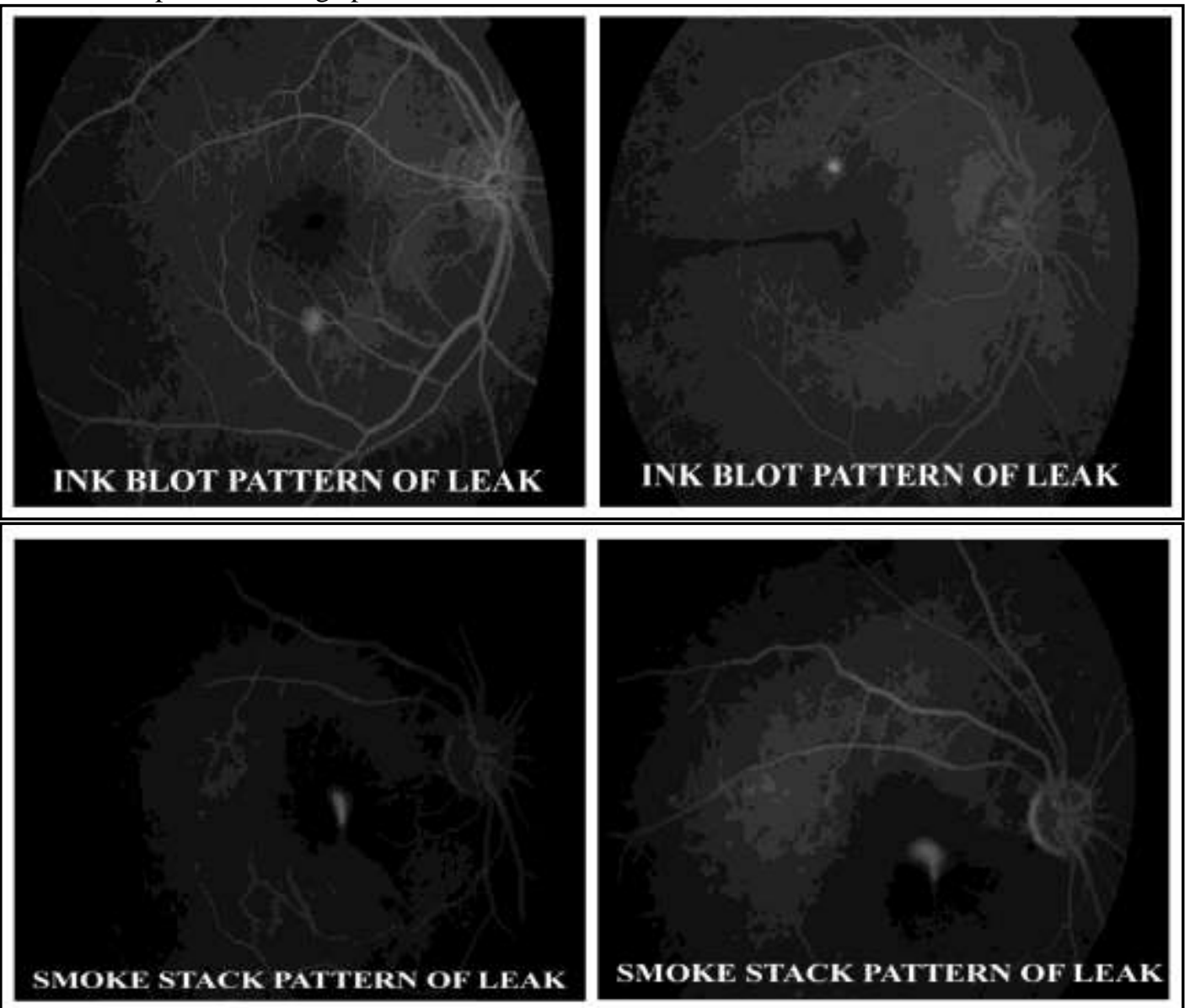

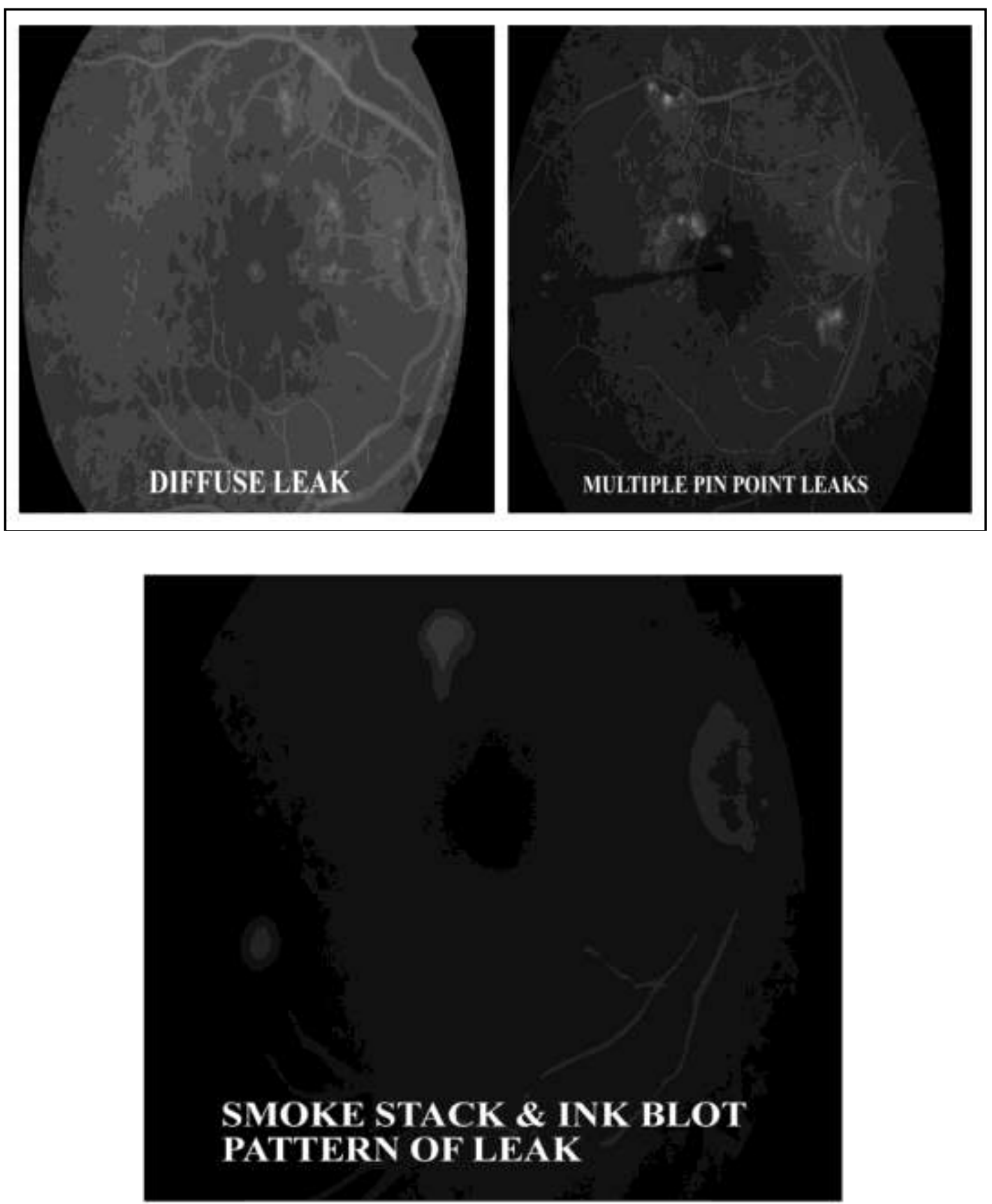

\section{Indocyanine Green Angiography:}

Corresponding to the pathologic changes seen during fluorescein angiography, increased fluorescence appears in the same location during ICG angiograms. ICGA findings during the middle phase about 10 minutes after the ICG injection were classified as intense or intermediate hyper fluorescence or as having no hyper fluorescence by Sawa etal, in chronic CSR patients. ICGA helps in locating the area of choroidal hyperpermeability which is the primary pathology, and helps in accurate localization for treatment. Studies have shown that areas of choroidal hyper permeability may be seen in asymptomatic eyes of patients with CSR and may not correspond to the area of leak on FA and may be further away from it. 


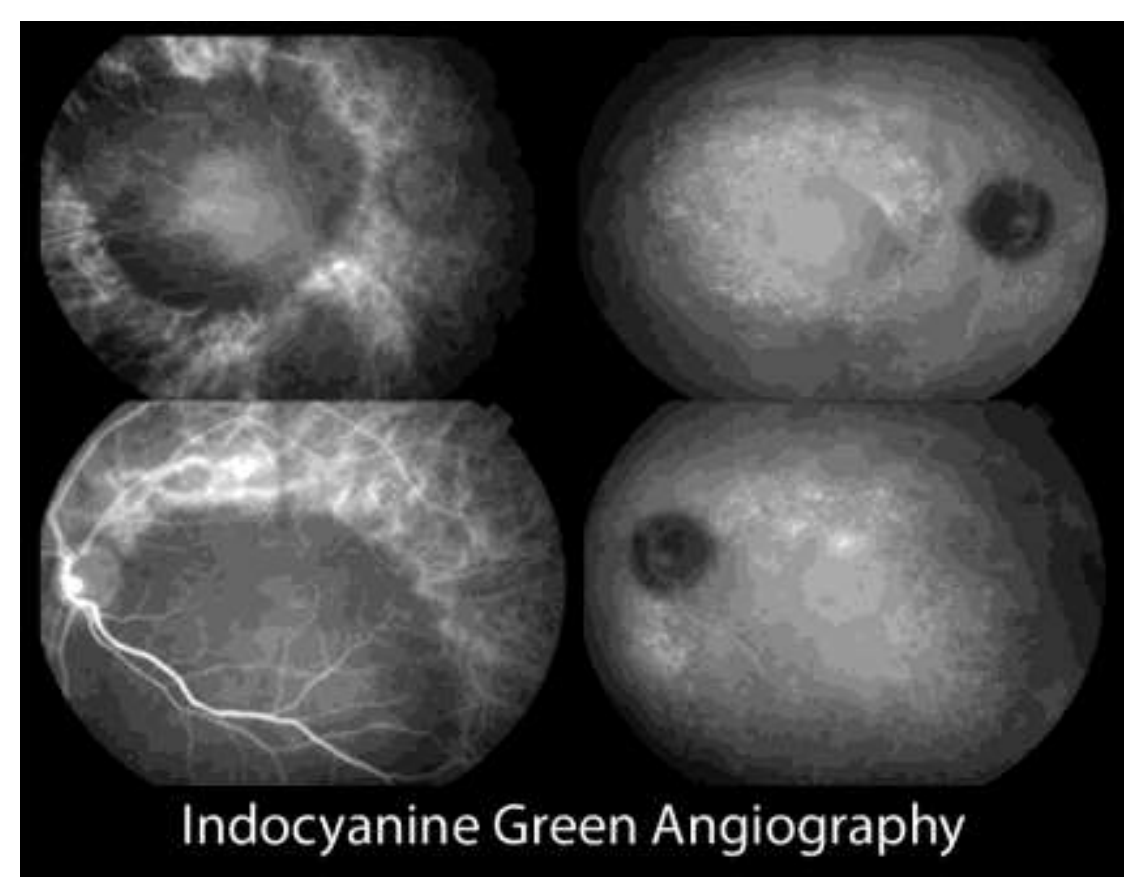

Optical coherance tomography:

OCT is traditionally used to quantify the amount and extent of the subretinal fluid, demonstrate thickening of the neural retina, RPE detachment, subretinal fibrin and is commonly used for diagnosing the changes in the neurosensory retina that can cause permanent impairment in vision in such eyes. Recently,3D-high speed OCT has shown to facilitate the understanding of pathophysiologic changes in CSCR. High resolution OCT detects shallow elevations of the retina, and not surprisingly, a thickening of thechoroid.

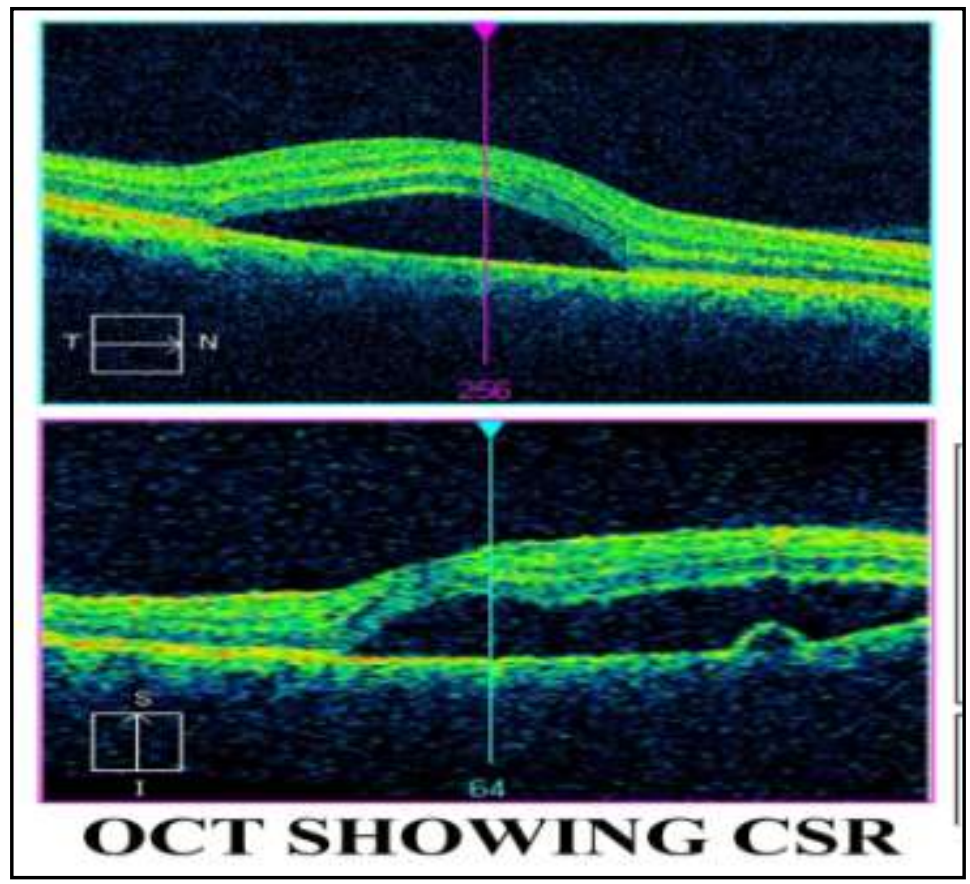

Fundus Autofluorescence:

Fundus autofluorescence abnormalities in CSCR show multiple distinct patterns and seem to provide functional information. Yultaka etal in their study of 475 eyes with CSR revealed that confluent hypo autofluorescence of the 
macula, granular hypo autofluorescence of the macula, and increasing age all were independent predictors of decreased visual acuity.

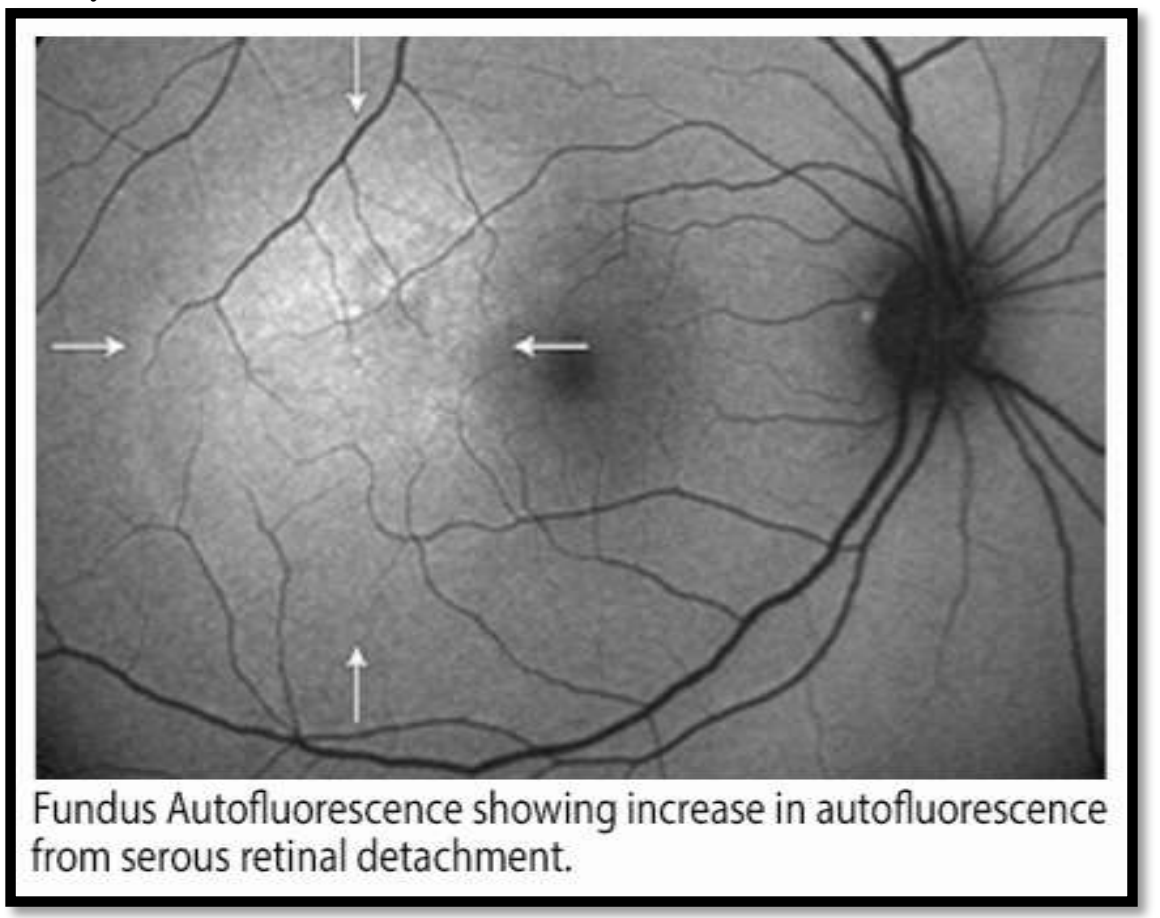

\section{Treatment:}

In a disease in which vast majority of cases are self-limiting with spontaneous healing, the efficacy of any form of treatment is detectable. But laser photocoagulation is the best method to treat focal leaks.

\section{Therapeutic approaches:}

Current and future treatment options of cscr

\section{Laser photocoagulation:}

Robertson and Ilstrup suggested a reduction in CSCR recurrences and shortening of the duration of detachment with the direct laser photocoagulation compared with sham or indirect (away from the site of leakage) photocoagulation within a follow up period of 18 months. Dellaporta concluded that untreated eyes were 3.3 times more likely to develop recurrence than treated eyes. Gilbert et al found no difference either in final visual acuity or in recurrence rate between eyes treated with argon laser photocoagulation and untreated eyes in their retrospective long term follow up study of CSCR patients.

\section{Criteria for selection for LASER}

An unequivocal diagnosis of CSCR must be made.

Fluorescein leakage must be demonstrated in the area or area immediate adjacent to the serous detachment.

Well defined leakage point must be demonstrable on FFA at least 500 microns away from the center of foveal avascular zone.

Progression of disease for 4 months or longer.

Patients with unclear ocular media.

One eyed patient where quality of work is being disturbed. 


\section{Recurrent CSCR.}

Unsatisfactory outcome in fellow eye without laser photocoagulation.

Visual acuity less than 6/12.

Local causes for serous detachment like adjacent hemangioma, melanoma, congenital pits of the optic disc, and choroidal inflammation etc. must be excluded.

\section{Technique:}

Before photocoagulation, visual acuity, Amsler grid tests are checked. Pupil is maximally dilated. 2 or 3 burns are directed to the leakage site using a 200-micrometer spot size with exposure of 0.25 second and a low moderate intensity burn is produced by looking for mild greying of retinal pigment. The energy level of photocoagulator is set at the minimum and then gradually increased.

Complications are accidental foveal burn, and persistent scotoma in the field of vision if large area is photocoagulated.

\section{Photo dynamic therapy:}

Use of PDT with verteporfin and PDT was first reported in 2003 in CSCR cases by Yannuzi et al. several investigators have begun to use PDT as a first line therapy for CSCR, but it is still experimental.

\section{Micro pulse diode laser photocoagulation:}

Sub threshold micro pulse diode laser $(810 \mathrm{~nm})$ has recently been assessed for the treatment of chronic CSCR. It scores over conventional laser in having minimal or no collateral damage. It has been used in chronic disease with definite leak or diffuse leak.

\section{Transpupillary therapy:}

Shakula et al performed TTT in long standing CSCR, which resulted in the resolution of CSCR with sub foveal angiographic leaks and significant improvement in visual outcome, in comparison with the natural history of persistent CSCR. Long term results are unknown.

\section{Bevacizumab:}

Bevacizumab (Avastin) is an anti- VEGF (vascular endothelial growth factor) drug. This drug is directly injected to the vitreous of the eye. Now a day's this injection is utilized in CSCR cases to reduce the choroidal hyper permeability and reverse the changes. Originally it

\section{Acknowledgnent:-}

I am thankful to the Principal, Medical College, Thiruvananthapuram for providing an opportunity to carry a project work.

I express my sincere gratitude to Dr. P.S Girija Devi, Director, RIO, Thiruvananthapuram for her timely support, without which this project could not have been successfully completed.

I also express heartfelt thanks to Dr. Biju John, Dr. Edwin James, Dr. Anuja Sathar, Dr. Nimi Rajagopal, Dr. Beena Thankappan, Dr. Valsa T Stephan, Dr. Radhika for the many useful discussions.

I am thankful to Ms. Vijayakumari, Senior Ophthalmic Assistant, RIO, Thiruvananthpuram for her valuable helps.

I would like to thank Ms. Beena \& Ms. Sumitha, Staff Nurses, RIO, Thiruvannathapuram for their valuable helps.

I wish to thank all the faculty in the School Of Optometry for their support and encouragement during the project.

I modestly thank all the post graduates in the Department Of Ophthalmology for their kindness and willingness to help me during the project. 
I express my thanks to Sree Dhanya, Librarian, RIO, Thiruvananthapuram.

I am thankful to my classmates and juniors for their invaluable support during this study.

I sincerely thank to my parents and brothers for their love and support without which this study would not have been possible.

Last but not least I would like to sincerely thank all the patients enrolled in this study who co-operated most willingly for the completion of the study.

Above all I am thankful to the LORD ALMIGHTY for his blessings which helped me to conduct this study

\section{Financial implications:}

NIL

\section{Conflict interest:}

no conflict of interest. 